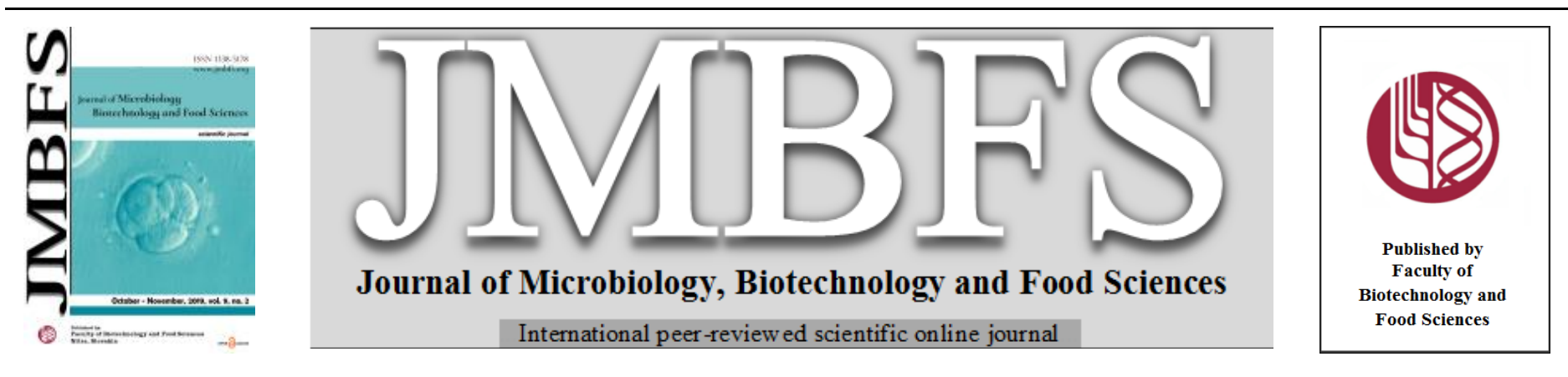

\title{
EFFECT OF PLANT HORMONES ON THE PRODUCTION OF BIOMASS AND LIPID EXTRACTION FOR BIODIESEL PRODUCTION FROM MICROALGAE Chlorella Sp.
}

\author{
Prakash Bhuyar ${ }^{1}$, Mashitah M. Yusoffl, Mohd Hasbi Ab. Rahim ${ }^{12}$, Sathyavathi Sundararaju ${ }^{3}$, Gaanty Pragas Maniam ${ }^{12}$, \\ Natanamurugaraj Govindan ${ }^{12 *}$
}

Address(es): Dr. Natanamurugaraj Govindan

${ }^{1}$ Algae Culture Collection Center \& Laboratory, Faculty of Industrial Sciences \& Technology, Universiti Malaysia Pahang, Lebuhraya Tun Razak, 26300 Gambang, Kuantan, Pahang, Malaysia.

${ }_{2}^{2}$ Earth Resources and Sustainability Centre (ERAS), Universiti Malaysia Pahang, Lebuhraya Tun Razak, 26300 Gambang, Kuantan, Pahang, Malaysia.

${ }^{3}$ Department of Pathology, Sidra Medicine, Doha -26999, Qatar.

*Corresponding author: natanam@ump.edu.my

doi: 10.15414/jmbfs.2020.9.4.671-674

\section{ARTICLE INFO}

Received 16. 5. 2019

Revised 24. 6. 2019

Accepted 11. 9. 2019

Published 3. 2. 2020

\section{Regular article}

open $\partial_{\text {ACCESS }}$

\begin{abstract}
The economic globalization and rapid energy depletion require alternative forms of energy which is more reliable, sustainable and renewable without causing adverse effects to the life forms. Microalgae are currently considered to be one of the most promising alternative sources for biodiesel and the application of phytohormones has also been considered a promising way to increase the production of lipid from microalgae recently. The present study is aimed to cultivate the algal species, Chlorella as a feedstock and the effect of various concentrations of phytohormones such as 6-Benzylaminopurine (BAP), Gamborg's b-5 vitamins, Indole-3-butyric acid (IBA), 2, 4-Dichlorophenoxyacetic acid (2,4-D) was used for the production of lipid. The extracted lipid oils were then converted into methyl ester via the transesterification process. Indole-3-butyric acid (IBA) relatively supported the maximum growth of $7.185 \mathrm{~g} / \mathrm{ml}$ and the lipid yield was $3.5 \mathrm{~g} / \mathrm{ml}$. The GC-MS characterization showed many peaks corresponding to the fatty acid methyl esters. Among those Ethylbenzene, o-Xylene, Benzene,1,2,4-trimethyl and Decane peaks of hydrocarbons were found important in the biofuel production. The current study demonstrates that the phytohormone IBA accelerate the microalgae growth and also induce the production of lipid oils for biodiesel production.
\end{abstract}

Keywords: Plant growth hormones, Microalgae, Biodiesel, Lipid oil

\section{INTRODUCTION}

The biofuel production from renewable sources can decrease fossil fuel dependency and support to maintain the healthy environment and economic stability. Biofuels are non-lethal, biodegradable and have less Green House Gaseous releases (Bhuyar $\mathbf{P}$, et al., 2018) when charred in combustion engines than obligatory fossil fuels (Beer, 2009). Biodiesel is most characteristically a mixture of fatty acid alkyl monoesters produced through the chemical conversion of triglycerides from vegetable oils and fats that have alike structures to Petro diesel (Cheng and Timilsina, 2011). Microalgae are currently considered to be one of the most promising alternative sources for biodiesel (Sheehan et al., 1998). Microalgae, a potential renewable source with many promising characteristics to produce biodiesel. They have tremendous attention due to rapid growth with limited growth requirements and high oil content (Maadane et al., 2017). Microalgae also involved in reduction of inorganic pollutants from wastewater (Bhuyar et al., 2019). These microalgae responsible for environmental protection and reduction of the global warming (Lababpour, 2018).

However, cultivating microalgae for biodiesel production at large scale is still a challenging part as there is an increase in demand for freshwater for various purposes (Lekshmi et al., 2015). There are many advantages of using microalgae for the feedstock like the ease of cultivation, low requirements of the growth media (Chisti, 2007; Meng et al., 2009). Microalgal oil can be converted into bio-oil, bioethanol, biohydrogen and biomethane via thermochemical and biochemical processes. Microalgal biodiesel appears to be of high potential for biodiesel production because of genetically increasing of the lipid content of the microalgae (Huang et al., 2010).

Microalgae oil can include carbohydrates, amino acids, proteins, nucleic acid etc. the secondary metabolites are of high value as polymeric carbohydrates, poly unsaturated fatty acids (PUFA), lutein etc. there is an interest in a high scale harvesting of microalgae for bio mitigation of $\mathrm{CO} 2$ (Gallagher, 2011) and the sustainable making of biofuels (Yangmin and Mulan, 2011) but purification of crude biodiesel using membrane technologies is mandatory for biodiesel production (Atadashi, 2015). Depending on species, microalgae produce many kinds of lipids, hydrocarbons, and other complex oils (A. Banerjee et al., 2002; P. Metzger and C. Largeau, 2005). The major lipid components in all algal species were triglycerides, monogalactosyl, digalactosyl and sulphoquinovosyl diglycerides, phosphatidyl glycerol, phosphatidyl choline (lecithin), and phosphatidyl ethanolamine; while palmitoleic, palmitic, eicosapentaenoic and eicosate-traenoic acids were the major fatty acid constituents (Oraei M et al., 2019). Part of the fixed $C$ from the atmosphere is stored in various lipid forms, including triacyl glycerides (TAGs), free fatty acids, sterols and wax esters up to $60 \%$ of dry cell material in some strains (Q. Hu, et al.,2008) Triglycerides, a major neutral lipid can be used to produce the biodiesel from algae.

The objective of this research is the analysis of the growth of microalgae in the different concentration of phytohormones such as 6-Benzylaminopurine, 2,4Dichlorophenoxyacetic acid, Indole-3-butyric acid and Gamborg's B-5 vitamins. To analyze the lipid content of treated microalgae by transesterification process This microbial oil is finally converted to biodiesel which can supposedly be used as a new generation transportation fuel, once the production process is established for large scale.

\section{MATERIAL AND METHODS}

\section{Sample collection and Isolation of microalgae}

The microalgal samples were collected from the Kuantan coast, Malaysia which were rich in oil laden microalgae. The sample was first grown in BG11 media plate. After few days the colony was again selected from the streak and were cultured in culture flask of 2 liter containing $500 \mathrm{ml}$ of BG 11 media. The light and dark hours of 12:12 was maintained and the light intensity of 5000 lux was used. The temperature was kept $25^{\circ} \mathrm{C}$. 


\section{Strain identification}

Identification of species generally require a blend of morphological and gene characterizations (Estep and MacIntyre, 1989). Depending on species, microalgae produce various kinds of lipids, hydrocarbons and other complex oils (Spolaore et al., 2006). The strain was identified by firstly using fluorescent microscope and then confirming by Scanning Electron Microscope.

\section{Stock preparation and Mass cultivation of microalgae}

The culture from the 2-liter flask was sub cultured for the mass cultivation. BG11 media was prepared and divided in 2 Liters numerous flasks. The inoculum from the prior culture was added to all the flasks. The flasks were maintained under different concentrations of 4 different phytohormone namely: 6 Benzylaminopurine (BAP), Gamborg's b-5 vitamins, Indole-3-butyric acid (IBA), 2, 4-Dichlorophenoxyacetic acid (2,4-D). The stock solution of different concentration was added $(1 \mathrm{ml})$ to each flask containing the inoculated BG11 media contains $\mathrm{NaNO}_{3}: 1 \mathrm{~g} / \mathrm{L} ; \mathrm{K}_{2} \mathrm{HPO}_{4}: 0.25 \mathrm{~g} / \mathrm{L} ; \mathrm{MgSO}_{4}: 0.513 \mathrm{~g} / \mathrm{L} ; \mathrm{FeCl}_{3}$ : $0.0058 \mathrm{~g} / \mathrm{L} ; \mathrm{CaCl}_{2}: 0.058 \mathrm{~g} / \mathrm{L}$; Agar: $15 \mathrm{~g} / \mathrm{L}$. The $\mathrm{pH}$ of the media was adjusted for 7 and the light intensity was kept 5000 lux following a photoperiod of 12:12 light: darkness. The temperature was kept at $25^{\circ} \mathrm{C}$ which leads to optimum growth of microalgae. The flasks were kept in shaker with a $150 \mathrm{rpm}$ every alternate day to stop the sedimentation of the microalgae. A separate flask was kept with only the inoculated BG11 media which serves as the control.

\section{Growth analysis}

The growth of the microalgal cultures in the different phytohormone concentrations were measured using the spectrophotometric readings which is directly proportional to the chlorophyll present thus, gives the cell density. The triplicate readings were taken at $660 \mathrm{~nm}$. The readings were taken every day for a span of 16 days (Illman et al., 2000). The ANOVA (one way) analysis with Turkey test was done in the software ORIGIN Pro version 8.6 for statistical analysis.

\section{Microalgal harvesting}

The flasks with higher algae biomass was cultivated for lipid extraction and subsequent biodiesel production. The culture was taken and centrifuged at 6500 rpm for 15-20 minutes. The clear supernatant containing the media was rejected. The pellet was collected. The pellet was kept for freeze drying at $-80^{\circ} \mathrm{C}$ to obtain a dried mass of algae. This dry mass of algae was weighed, and further lipid extraction was performed by Bligh and Dyer lipid extraction method was followed.

\section{Transesterification}

Transesterification produces methyl esters of fatty acids (biodiesel), and glycerol. This reaction is a step wise reaction where the triglycerides are converted initially to diglyceride then to monoglyceride and finally to glycerol. A large excess of methanol is used so that the entire triglyceride is converted into methyl ester and the reaction moves forward to the methyl-ester formation (Shah and Sharma, 2003). Yield of methyl esters exceeds $98 \%$ on a weight criterion (Balat, 2008) This reaction is catalyzed by methoxide ( $1 \%$ by weight $\mathrm{KOH}$ mixed to methanol) which serves to decrease the reaction time (Alamu et al., 2007). The reaction is carried out at $70-75^{\circ} \mathrm{C}$ at atmospheric pressure. The lower phase contains the glycerol and the upper phase contains the methyl esters (biodiesel). The upper phase was collected. This was used for further characterization. The percentage harvest of biodiesel was calculated using the Equation.

Harvest of biodiesel $(\%)=($ grams of biodiesel obtained/ grams of oil utilized $)$ $* 100$

$$
\begin{aligned}
& =(3.5 / 6) * 100 \\
& =58.3 \%
\end{aligned}
$$

\section{Gas Chromatography with Mass Spectrum (GC-MS)}

The content of algae biodiesel (fatty acid methyl esters) produced was determined by GC MS using the Agilent 5973 inert gas chromatograph/ mass spectrometer for identifying the fatty acid compositions (Wahidin and Shaleh, 2013). Gas chromatogram is used to differentiate the sample into individual component using temperature controlled capillary column. Mass spectrometer provides the molecular weight and structural formula of the compounds by measuring and comparing the unique mass spectrum $(\mathrm{m} / \mathrm{z})$ of the fragment with NIST standard library (Marín-Suárez et al., 2010). The GC and GC-MS method provides the separation, identification and estimation of the polyunsaturated fatty acid methyl esters (PUFA) using an exceedingly polar capillary column (100\% cyanopropyl silicon) which permits the separation of fatty acid methyl esters having very adjacent boiling points, cis/ trans isomers and olefinic positional isomers. The run time was 31 minutes with an initial temperature of $250^{\circ} \mathrm{C}$ and a pressure of 12.47 psi. Split inlet flow with a split ratio of 10:1 and a split flow of
$9.9 \mathrm{ml} / \mathrm{min}$ was used. The inert gas helium was used as carrier gas. The injection volume of $1 \mu \mathrm{l}$ was used for the analyses. The MS analysis mode was used in relative EMV mode with a resulting EM voltage of 1282 . The fatty acid methy esters were recognized by gas chromatography united with mass spectrometry (Zhao et al., 2011; Abdulla and Ravindra, 2013). The NIST mass spectral library was used for recognizing of components in the samples.

\section{RESULTS AND DISCUSSION}

\section{Isolation and identification of microalgae}

In this experiment, the microalgal samples collected from the Kuantan coast, Malaysia were phototrophically grown in the media BG11 and its growth rate was measured. The species identification was done in a systematic way by using fluorescent and scanning electron microscopic analysis. Figure-1 was referred to the microalgal library and tallying the morphological structures and shapes the strain was found to be Chlorella sp. as it was observed as a single-celled green alga belonging to the class of Chlorophyceae.
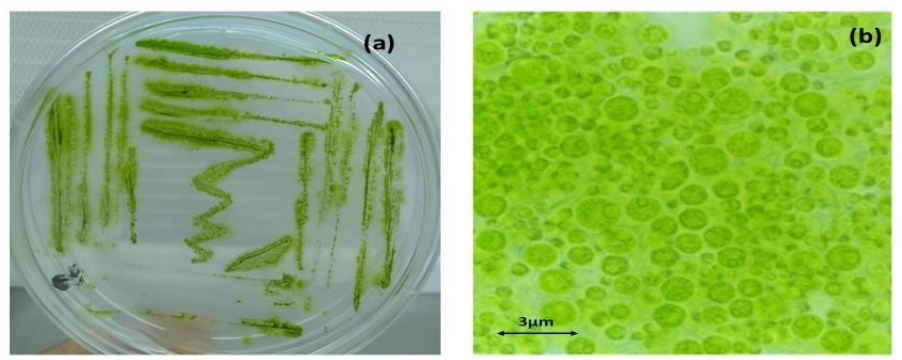

Figure 1 (a) Spread Plate of algal sample on BG11 agar media. (b) Fluorescent microscope image of Chlorella sp. (at 100X)

To further confirm the strain, the culture was analyzed in FE-SEM. The sample slide was prepared, and the double-sided conductive carbon tape was fitted on the rear side of the slide. This slide was mounted, and the analysis was done in JSM $7800 \mathrm{~F}$. This was to support the findings from fluorescent microscope. The sample atoms interact with the electron from the electron source and thus gives information about the sample's topography and composition. The FE-SEM gives topographical and elemental information at high magnifications and virtually unlimited depth of field thus confirming the species to be Chlorella sp.
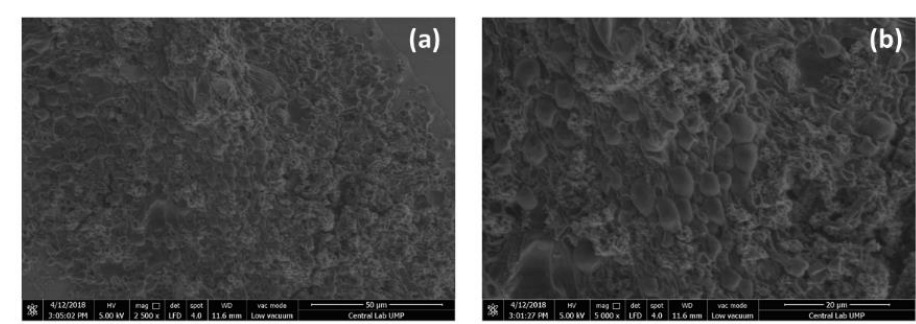

Figure 2 (a) FE-SEM image of Chlorella sp. At 2500X magnification. (b) FESEM image of Chlorella sp. at 5000X magnification.

\section{Growth analysis}

The isolated Chlorella sp was cultivated with different concentrations of plant hormones. The cell density was quantitatively measured the optical density of each sample at $660 \mathrm{~nm}$ by using UV-Vis spectrophotometer (GENESYS 10S). The amount of chlorophyll signifies the total algal content in the cultures. Figure3 showed the spectrophotometric readings of samples measured every $12 \mathrm{hr}$ for a span of 16 days by placing the different culture samples under different concentration of phytohormone in a cuvette and taking a triplicate reading following the method of Illman et al., (2000).

The concentration range of phytohormones such as BAP (6-Benzylaminopurine), Gamborg's B-5 vitamins, IBA (Indole-3-butyric acid), 2,4-D (Dichlorophenoxyacetic acid) and used in this study were between $0.2-1 \mathrm{mg} / \mathrm{ml}$, 0.5 to $2 \mathrm{mg} / \mathrm{ml}, 0.5$ to $2.0 \mathrm{mg} / \mathrm{ml} \& 0.5$ to $1.5 \mathrm{mg} / \mathrm{ml}$ respectively.

BAP (6-Benzylaminopurine): There was no significant effect on growth at $0.2 \mathrm{mg} / \mathrm{ml}$ concentration of BAP (6-Benzylaminopurine) until 9th day of incubation. We observed an exponential increase in growth rate at $0.6 \mathrm{mg} / \mathrm{ml}$ of concentration, whereas the growth rate was very low at $1 \mathrm{mg} / \mathrm{ml}$ concentration. The increase in the cell density is progressive till the 14th day where there is a sudden decrease in the optical density on 16th day of incubation. But its growth is again increased on the successive day which proves that the decrease in the growth could be a technical error in sampling of the culture (Demirbas, 2009).

Gamborg's B-5 vitamins: The flask with $0.5 \mathrm{mg} / \mathrm{ml}$ of Gamborg's B-5 vitamins had sturdy rise in the growth especially on 5th day. The growth decreases starting from 9th day and thus the microalgae have reached decline phase. At the 
concentration of $1 \mathrm{mg} / \mathrm{ml}$ phytohormone showed fairly considerable growth and the decline phase have been reached by the 10th day which shows the inability of the microalgae to survive in this concentration of phytohormone. The flask with $1.5 \mathrm{mg} / \mathrm{ml}$ of phytohormone showed the exponential phase till the 9th day after which there was a stationary phase till 11th day and the growth was declined phase from 12 th day. The flask with $2 \mathrm{mg} / \mathrm{ml}$ of phytohormone shows very little rise during the initial days. It reaches the stationary phase at a very low optical density and the decline phase sets in from day 11 .

IBA (Indole-3-butyric acid): At $0.5 \mathrm{mg} / \mathrm{ml}$ concentration of IBA (Indole-3butyric acid), there was an exponential growth in the cell density till 13th day after which the cell growth was deteriorated. At $1 \mathrm{mg} / \mathrm{ml}$ concentration, the cell growth showed stable growth and there was no decline in its growth. The growth was exponential at $1.5 \mathrm{mg} / \mathrm{ml}$ concentration of phytohormone, and it reached the highest cell density among all other concentrations of other phytohormones used in this study. At $2 \mathrm{mg} / \mathrm{ml}$ of the phytohormone concentration, there was a slow increase in optical density which might be because of higher concentration which adversely affect the cell growth. The Chlorella sp. containing IBA with 1,5 $\mathrm{mg} / \mathrm{ml}$ was considered for the further biomass and lipid production.

2,4-D (Dichlorophenoxyacetic acid): The flasks with 2, 4-D with $0.5 \mathrm{mg} / \mathrm{m}$ concentration showed an increasing growth until 11th day and the density of cells were reduced from 12th day onwards. At $1 \mathrm{mg} / \mathrm{ml}$, there was a rise in the optical density which is not strident, the deterioration phase starts from 14th day. The $1.5 \mathrm{mg} / \mathrm{ml}$ concentration shows substantial growth and reached stationary phase from the 11th day and also showed a slight upsurge on 13th and 14th day and again reaches a stationary phase from 15 th day.

Microalgae grown with IBA phytohormones showed exponential growth and it reaches the highest cell density among all other concentrations of the differen phytohormones used in this study and it was further processed for the harvesting.

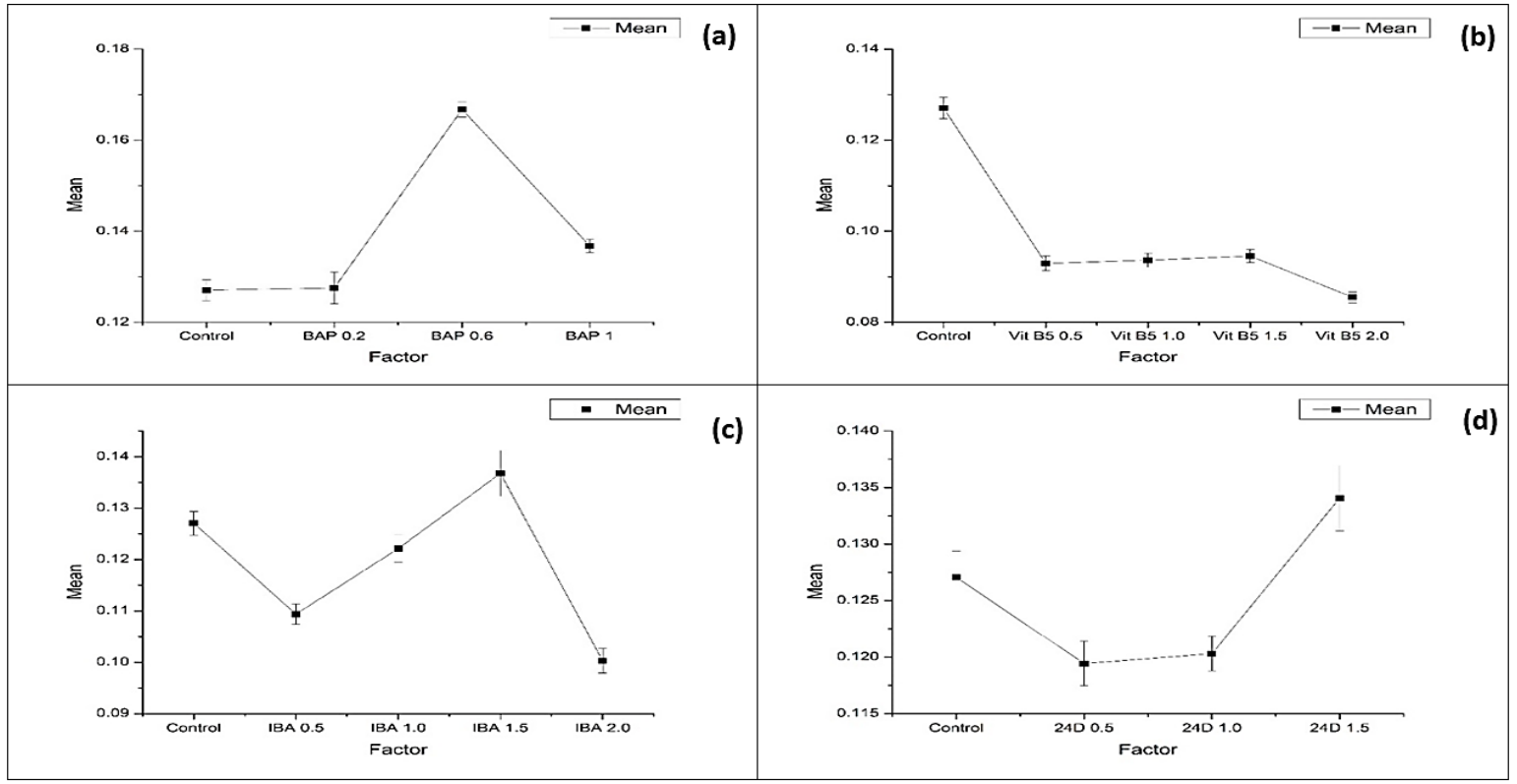

Figure 3 Statistical analysis (a) Graph of ANOVA for BAP. (b) Graph of ANOVA for Gamborg's vit b-5 (c) Graph of ANOVA for IBA. (d) Graph of ANOVA for 2,4-D

\section{Microalgal harvesting}

Microalgae with IBA showed higher growth rate than other phytohormones used. Harvesting of the mass cultivated microalgae with the effect of IBA $(1.5 \mathrm{mg} / \mathrm{ml}$ or $0.75 \mathrm{mg} /$ liter) was done. The stock solution of $1.5 \mathrm{mg} / \mathrm{ml}$ was added into about five different 2 -liter flasks for harvesting $90.75 \mathrm{mg} /$ liter. The culture was divided into centrifuge tubes and centrifuged at $6500 \mathrm{rpm}$ for $15-20$ minutes to separate algal pellets from culture media. The collected pellets were kept for freeze drying at $-80^{\circ} \mathrm{C}$ to obtain dried algal biomass. The freeze-dried algal biomass was directly sublimate from solid phase to gas phase. After this process, algal pellet was weighed, and we obtained approximately $7.185 \mathrm{~g} / \mathrm{L}$. The collected algal pellet was used for lipid extraction.
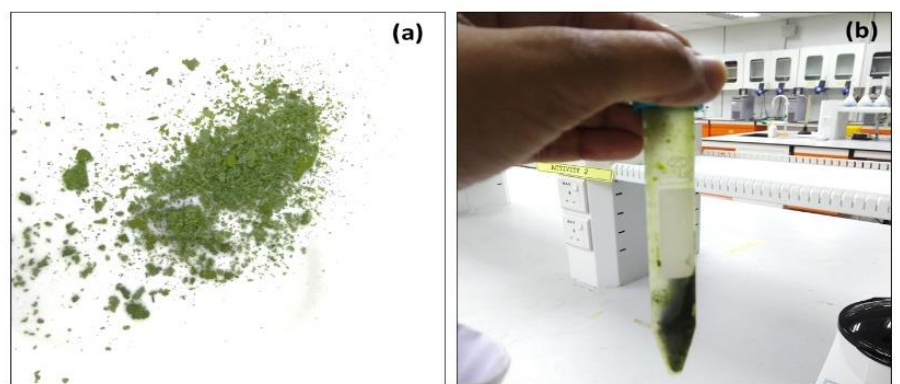

Figure 4 (a) Dried algal biomass. (b) Pellet formation (6500 rpm for 15 minutes)

\section{Lipid extraction}

Solvents such as chloroform and methanol in a ratio of $1: 2$ were mixed with the dried algal biomass and vortexed for 60 seconds. It was then centrifuged at 4000 rpm for 15 minutes. After centrifugation, the upper phase was discarded as it contains the mixture of methanol and water. The lower phase contains the lipid derived from the microalgae mixed in the chloroform phase (Figure-5). The lower phase with lipid was collected carefully in a separate petri plate and dried under liquid nitrogen to evaporate the solvent leaving behind the lipid following the method of Demirbas, (2009); Jonker and Faaij, (2013).

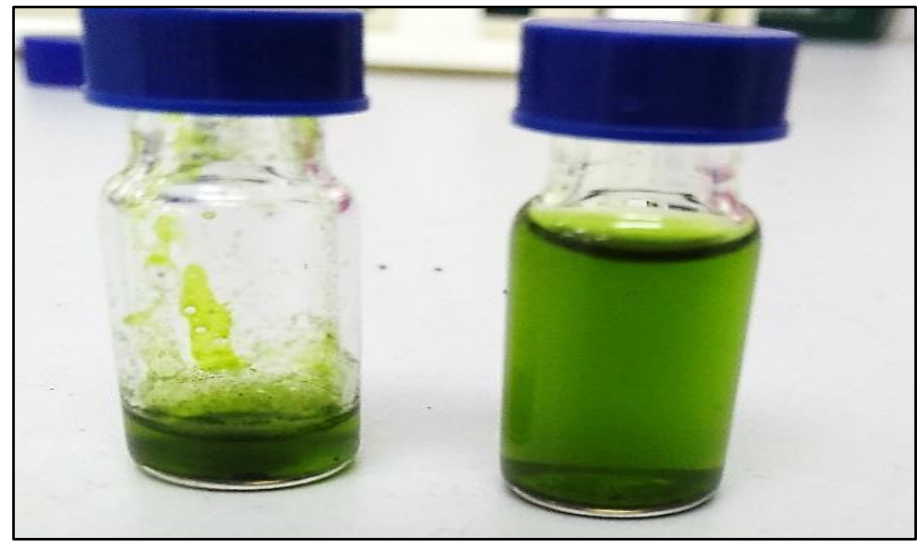

Figure 5 Microalgal oil after liquid nitrogen drying of the chloroform phase.

After the completion of the reaction the phase differences are seen. The product is left to settle in a phase separating funnel for about 4 hours which gives two separate phases. The upper phase is the desired methyl ester containing phase The weight of the oil was found to be $3.5 \mathrm{gm}$. The lower phase has the glycerol.

\section{Gas Chromatography with Mass Spectrum (GC-MS)}

Further GC-MS characterization was done. The chromatogram has showed 14 peaks (Figure 6). Benzene, 1-ethyl-4-methyl- Cyclohexasiloxane, Dodecamethyl Pentasiloxane, dodecamethyl Benzeneacetic acid, alpha.,3,4tris[(trimethylsilyl)oxy]-, trimethylsilyl ester, Cyclononasiloxane, octadecamethyl-, Benzo[h]quinoline, 2,4-dimethyl- Pentafluorobenzoic acid organosilicon chemistry, and Octasiloxane, the initial peaks of hydrocarbons are important in the biofuel production. The similar observation by microalgae nannochloropsis was observed in Cheng and Timilsina, (2011). 


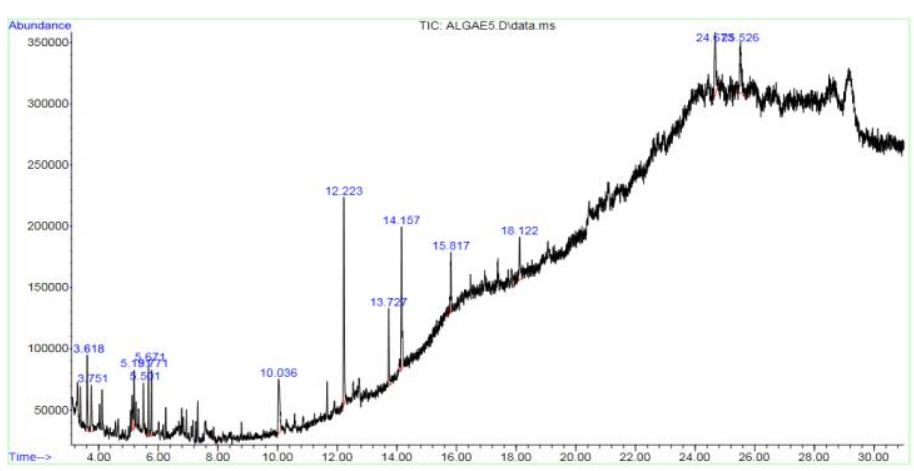

Figure 6 GC-MS chromatogram of the Fatty acid methyl ester obtained from the transesterification reaction.

Ethylbenzene, o-Xylene (ortho-xylene) and decane (alkane hydrocarbon) also observed from the chromatogram. These are the important constituent of gasoline (petrol) and kerosene. The total percentage being 4.791, maximum percentage 28.49. $\mathrm{RT}$ is at 5.671. 1, 2, 4-Trimethylbenzene (aromatic hydrocarbon) is a flammable liquid. It is found naturally in coal tar and petroleum (about 3\%). for the hydrocarbon-based products. It also helps in inhibiting the freezing of the fuels in the fuel tank gum up in aviation fuels (Nie et al., 2006; Beer et al., 2009). Among those Ethylbenzene, o-Xylene, Benzene,1,2,4-trimethyl and Decane peaks of hydrocarbons were found important in the biofuel production. Other considerations to make are the easier strain selection for the maximum lipid yield.

\section{CONCLUSION}

In the conclusion, the microalgal strain Chlorella $\mathrm{Sp}$. was isolated from Kuantan coast, Malaysia was mass cultivated in the presence of different phytohormones (6-Benzylaminopurine, 2,4-Dichlorophenoxyacetic acid, Indole-3-butyric acid and Gamborg's B-5 vitamins. Among these, Indole-3-butyric acid was a promising phyto hormone for the production of biomass and lipd oil as well for biodiesel production. The GC-MS analysis showed 14 peaks of different compounds including Ethylbenzene, o-Xylene, Benzene,1,2,4-trimethyl and Decane peaks of hydrocarbons were found to be an important compound for the biofuel production. It clearly shows that, there would be an interest from an application point of view if the study could expand the number of strains and studying the genome of this Chlorella Sp. would give additional clues for the effective production of lipid oils.

Acknowledgements: The authors gratefully acknowledged Universiti Malaysia Pahang for the financial assistance through the Internal Research Grant No. RDU1703167 and Flagship Grant No. RDU182205. Author [Prakash Bhuyar] is thankful to UMP for providing Doctoral Research Scholarship DRS as a financial support.

\section{REFERENCES}

Abdulla R, Ravindra P. (2013). Characterization of cross linked Burkholderia cepacia lipase in alginate and $\kappa$-carrageenan hybrid matrix. Journal of the Taiwan Institute of Chemical Engineers. 44(4):545-51. http://dx.doi.org/10.1016/j.jtice.2013.01.003

Alamu OJ, Waheed MA, Jekayinfa SO. (2007). Biodiesel production from Nigerian palm kernel oil: effect of $\mathrm{KOH}$ concentration on yield. Energy for Sustainable Development. 11(3):77-82. http://dx.doi.org/10.1016/s0973-0826(08)60579-7

Atadashi IM. (2015). Purification of crude biodiesel using dry washing and membrane technologies. Alexandria Engineering Journal. 54(4):1265-72. http://dx.doi.org/10.1016/j.aej.2015.08.005

Balat M, Balat H. (2009). Biogas as a Renewable Energy Source-A Review. Energy Sources, Part A: Recovery, Utilization, and Environmental Effects. 31(14):1280-93. http://dx.doi.org/10.1080/15567030802089565

Banerjee A, Sharma R, Chisti Y, Banerjee UC. (2002). Botryococcus braunii: A Renewable Source of Hydrocarbons and Other Chemicals. Critical Reviews in Biotechnology. 22(3):245-79. http://dx.doi.org/10.1080/07388550290789513 Beer LL, Boyd ES, Peters JW, Posewitz MC. (2009). Engineering algae for biohydrogen and biofuel production. Current Opinion in Biotechnology. 20(3):264-71. http://dx.doi.org/10.1016/j.copbio.2009.06.002

Bhuyar Prakash, Muniyasamy Sudhakar and Govindan, Natanamurugaraj. (2018) Green Revolution to Protect Environment - An Identification of Potential Micro Algae for the Biodegradation of Plastic Waste in Malaysia. World Congress on BIOPOLYMERS AND BIOPLASTICS \& RECYCLING Expert Opin Environ Biol 2018, Volume: $\quad 7$ DOI: 10.4172/2325-9655-C5-033, https://ssrn.com/abstract=3391802.

Bhuyar, P. et al. (2019). Antimicrobial Study of Algal Enzymes Extracted from Microalgae by Ultrasonication. http://dx.doi.org/10.2139/ssrn. 3356472

Cheng JJ, Timilsina GR. (2011). Status and barriers of advanced biofuel technologies: $\begin{array}{llll}\text { A review. } & \text { Renewable } & \text { Energy. } & \end{array}$ http://dx.doi.org/10.1016/j.renene.2011.04.031
Chisti Y. (2007). Biodiesel from microalgae. Biotechnology Advances. 25(3):294-306 http://dx.doi.org/10.1016/j.biotechadv.2007.02.001

Demirbas A. (2009). Political, economic and environmental impacts of biofuels: A

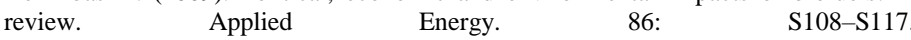
http://dx.doi.org/10.1016/j.apenergy.2009.04.036

Estep KW, MacIntyre F. (1989). Counting, sizing, and identification of algae using image analysis. Sarsia 74(4):261-8. http://dx.doi.org/10.1080/00364827.1989.10413433

Gallagher BJ. (2011). The economics of producing biodiesel from algae. Renewable Energy. 36(1):158-62. http://dx.doi.org/10.1016/j.renene.2010.06.016

Gong Y, Jiang M. (2011). Biodiesel production with microalgae as feedstock: from strains to biodiesel. Biotechnology Letters 33(7):1269-84. http://dx.doi.org/10.1007/s 10529-011-0574-z

Hu, Q., Sommerfeld, M., Jarvis, E., Ghirardi, M., Posewitz, M., Seibert, M., and Darzins, A. (2008). Microalgal triacylglycerols as feedstocks for biofuel production: perspectives and advances, Plant Journal., 54, 621-639. https://doi.org/10.1111/j.1365313X.2008.03492.x

Huang H, Yuan X, Zeng G, Wang J, Li H, Zhou C, et al. (2011). Thermochemical liquefaction characteristics of microalgae in sub- and supercritical ethanol. Fue Processing Technology. 92(1):147-53. http://dx.doi.org/10.1016/j.fuproc.2010.09.018 Illman A., Scragg A., Shales S. (2000). Increase in Chlorella strains calorific values when grown in low nitrogen medium. Enzyme and Microbial Technology. 27(8):6315. http://dx.doi.org/10.1016/s0141-0229(00)00266-0

Jonker JGG, Faaij APC. (2013). Techno-economic assessment of micro-algae as feedstock for renewable bio-energy production. Applied Energy. 102:461-75. http://dx.doi.org/10.1016/j.apenergy.2012.07.053

Lababpour A. (2018). A dynamic model for the prediction of flue gas carbon dioxide removal by the microalga Chlorella vulgaris in column photobioreactor. Alexandria Engineering Journal. 57(4):3311-20. http://dx.doi.org/10.1016/j.aej.2018.01.013

Lekshmi B, Joseph RS, Jose A, Abinandan S, Shanthakumar S. (2015). Studies on reduction of inorganic pollutants from wastewater by Chlorella pyrenoidosa and Scenedesmus abundans. Alexandria Engineering Journal. 54(4):1291-6. http://dx.doi.org/10.1016/j.aej.2015.09.013

Maadane A, Merghoub N, El Mernissi N, Ainane T, Amzazi S. (2017) ANTIMICROBIAL ACTIVITY OF MARINE MICROALGAE ISOLATED FROM MOROCCAN COASTLINES. Journal of Microbiology, Biotechnology and Food Sciences. 6(6):1257-60. http://dx.doi.org/10.15414/jmbfs.2017.6.6.1257-1260

Marín-Suárez M, Méndez-Mateos D, Guadix A, Guadix EM. (2019). Reuse of immobilized lipases in the transesterification of waste fish oil for the production of biodiesel. Renewable Energy. 140:1-8. http://dx.doi.org/10.1016/j.renene.2019.03.035 Meng X, Yang J, Xu X, Zhang L, Nie Q, Xian M. (2009). Biodiesel production from oleaginous microorganisms. Renewable Energy. 34(1):1-5 http://dx.doi.org/10.1016/j.renene.2008.04.014

Metzger P, Largeau C. (2004). Botryococcus braunii: a rich source for hydrocarbons and related ether lipids. Applied Microbiology and Biotechnology. 66(5):486-96. http://dx.doi.org/10.1007/s00253-004-1779-z

Nie K, Xie F, Wang F, Tan T. (2006). Lipase catalyzed methanolysis to produce biodiesel: Optimization of the biodiesel production. Journal of Molecular Catalysis B Enzymatic. 43(1-4):142-7. http://dx.doi.org/10.1016/j.molcatb.2006.07.016

Oraei M, Gohari G, Panahirad S, Zareei E, Zaare-Nahandi F. (2019). EFFECT OF SALICYLIC ACID FOLIAR APPLICATION ON Vitis vinifera L. cv. "SULTANA" UNDER SALINITY STRESS. Acta Scientiarum Polonorum Hortorum Cultus.18(2). http://dx.doi.org/10.24326/asphc.2019.2.15

Shah S, Sharma S, Gupta MN. (2004). Biodiesel Preparation by Lipase-Catalyzed Transesterification of Jatropha Oil. Energy \& Fuels. 18(1):154-9. http://dx.doi.org/10.1021/ef030075z

Sheehan J, Dunahay T, Benemann J, Roessler P. (1998). A look back at the U.S Department of Energy's Aquatic Species Program - biodiesel from algae. National Renewable Energy Laboratory, Golden, CO; 1998. Report NREL/TP-580-24190. https://doi.org/10.2172/15003040

Spolaore P, Joannis-Cassan C, Duran E, Isambert A. (2006). Commercial applications of microalgae. Journal of Bioscience and Bioengineering. 101(2):87-96 http://dx.doi.org/10.1263/jbb.101.87

Tan T, Lu J, Nie K, Deng L, Wang F. (2010). Biodiesel production with immobilized lipase: A review. Biotechnology Advances. 28(6):937. http://dx.doi.org/10.1016/j.biotechadv.2010.07.007

Wahidin S, Idris A, Shaleh SRM. (2013). The influence of light intensity and photoperiod on the growth and lipid content of microalgae Nannochloropsis $\mathrm{sp}$ Bioresource Technology. 129:7-11. http://dx.doi.org/10.1016/j.biortech.2012.11.032

Zhao, R. J. Lu, T. Tan. (2011). Preparation of poly (glycidyl methacrylate) macropore beads and application in candida species 99-125 lipase immobilization. Chem Eng Technol, 34, 93-97. https://doi.org/10.1002/ceat.201000263 